\title{
SENTINEL LYMPH NODE- A CAPTAIN IN THE MANAGEMENT OF ORAL SQUAMOUS CELL CARCINOMA
}

\author{
Triveni Bhopal1, Namdev Vadla², Sai Mallikarjun³, Sree Lakshmi ${ }^{4}$
}

1 Professor and HOD, Department of Pathology, MNJ Institute of Oncology and Regional Cancer Center, Hyderabad, Telangana, India. 2Postgraduate Student, Department of Pathology, MNJ Institute of Oncology and Regional Cancer Center, Hyderabad, Telangana, India. ${ }_{3}^{3}$ Assistant Professor, Department of Pathology, MNJ Institute of Oncology and Regional Cancer Center, Hyderabad, Telangana, India. ${ }^{4}$ Assistant Professor, Department of Pathology, MNJ Institute of Oncology and Regional Cancer Center, Hyderabad, Telangana, India. ABSTRACT

\section{BACKGROUND}

Squamous cell carcinoma represents about 2-3\% of all malignant neoplasms \& 47\% of those arising in Head \& Neck area. Incidence of Oral Squamous Cell Carcinoma is increasing especially in young people. The status of lymph node involvement holds prime importance in the prognosis and therapy of Oral Squamous Cell Carcinoma (OSCC). The risk of neck metastasis depends on the site, size, grading and depth of infiltration of tumour. Neck dissection is the only surgical option for pathologic staging of neck in patients with OSCC. However, often a minimally invasive sentinel lymph node biopsy may be adequate. Sentinel Node biopsy is a novel useful technique alternative to neck dissection in the management of OSCC. Sentinel lymph node offers accurate staging with minimal morbidity. Selective excision, meticulous histopathological examination of sentinel lymph nodes play a very important role in preserving the surgical approach to a $\mathrm{N}_{0}$ carcinoma. Aim of this study was to evaluate the role of sentinel lymph node in staging and treatment of Oral Squamous Cell Carcinoma in a Tertiary cancer care center.

\section{MATERIALS \& METHODS}

In diagnosed cases of Oral Squamous Cell Carcinoma, sentinel lymph node excision was done prior to planned radical neck dissection, to study its role in staging of OSCC. Localization of sentinel lymph nodes done by using methylene blue dye and their histopathological examination was done by following step serial sectioning to detect lymph nodal micro metastasis for appropriate staging and management.

\section{RESULTS}

20 cases with diagnosis of Well Differentiated Oral Squamous Cell Carcinoma were taken for study. Number of sentinel lymph nodes varied from one to five. Out of 20 cases, sentinel lymph nodes were identified in 16 cases. In those 16 cases, 6 cases were positive for metastasis on routine histopathological evaluation. The remaining 10 cases which were negative for metastasis, were later subjected to step serial sectioning. After which 1 case turned out to be positive.

\section{CONCLUSION}

Centers practicing sentinel lymph node biopsy for staging of Oral Squamous Cell Carcinoma should have meticulous histopathological workup on the entire lymph node by using step serial sectioning and there by detect micro metastasis and isolated tumour cells if any, to avoid unnecessary radical neck dissection and postoperative morbidity associated with it.

\section{KEY WORDS}

OSCC, Sentinel Node, Sentinel Lymph Node Biopsy, Micro Metastasis.

HOW TO CITE THIS ARTICLE: Bhopal T, Vadla N, Mallikarjun S, et al. Sentinel lymph node- a captain in the management of oral squamous cell carcinoma. J. Evolution Med. Dent. Sci. 2018;7(51):5452-5455, DOI: 10.14260/jemds/2018/1206

\section{BACKGROUND}

Oral Squamous Cell Carcinoma represents about 2-3\% of all malignant neoplasms \& $47 \%$ of those arising in head and neck region. 1 Tobacco and its related products, alcohol, genetic and hormonal factors are causative. ${ }^{2}$ Early detection and accurate staging are crucial for adequate treatment and a better prognosis.

One of the properties of oral cancer is high frequency of metastasis, usually to the cervical lymph nodes.

'Financial or Other Competing Interest': None.

Submission 09-11-2018, Peer Review 04-12-2018,

Acceptance 10-12-2018, Published 17-12-2018.

Corresponding Author:

Dr. Namdev Vadla,

S/o. V. Hanmandlu,

H. No. LIG-47,

New Housing Board Colony,

Vinayaka Nagar, Nizamabad-503003,

Telangana, India.

E-mail: drnamdevv786@gmail.com

DOI: $10.14260 /$ jemds/2018/1206
Positive nodes are usually palpable and are easily identified clinically, whereas in clinically negative nodes, there is a chance of micro metastasis and isolated tumour cell deposits, which cannot be detected even on radiological imaging. ${ }^{3,4}$ Because of its high metastatic potential of these tumours, the presence of metastasis to a single regional lymph node can transform its stage from stage I tumour to an advanced stage III or even stage IV head and neck cancer. And the presence of a single positive lymph node can decrease disease free survival at 5 years by $50 \%$. Hence, in order to perform an adequate treatment of the neck, a correct diagnosis and staging are crucial for determining prognosis.5,6 Sentinel lymph node biopsy offers accurate detection of lymph node metastasis and accurate staging with minimal morbidity. Sentinel lymph node is defined as the lymph node on the direct drainage pathway from the primary tumour. When the tumour begins to metastasize, sentinel lymph nodes will be the first to get invaded before subsequent nodes are involved. ${ }^{7}$ There may be multiple sentinel lymph nodes and they need not be those closest to the tumour. ${ }^{8}$ 
Neck dissection is the only surgical option for pathologic staging in oral squamous cell carcinoma. However, sentinel lymph node biopsy, a minimally invasive procedure may be adequate with the help of meticulous histopathological examination. ${ }^{9}$

Aim of our study was to do histopathological evaluation of metastatic deposits to the sentinel lymph nodes by step serial sectioning, and to establish the role of sentinel lymph node in staging and management of oral squamous cell carcinoma.

\section{MATERIALS AND METHODS Study Design}

Diagnostic descriptive study.

Study included 20 cases of biopsy proven T1/T2 stage Oral Squamous Cell Carcinoma, in whom elective neck dissection was planned. This was a diagnostic descriptive study done in MNJ institute of Oncology and Regional Cancer Center, Hyderabad, over a period of 1 year from $1^{\text {st }}$ August 2015 to July $31^{\text {st }} 2016$. All of them underwent intraoperative sentinel lymph node mapping with blue dye for sentinel node biopsy just before the neck dissection. $5 \mathrm{ml}$ of $1 \%$ methylene blue dye was injected in to the mucosa around either the tumour mass or around the previous biopsy site just before the surgery. After 5-10 minutes duration of injecting the dye, neck flap was raised. Blue stained lymph nodes were appreciated, dissected out and sent for histopathological examination. ${ }^{10}$ (Method of sentinel node removal depicted in Figure 1)

After removal of sentinel lymph node, the routine planned neck dissection was performed. The sentinel lymph nodes which were sent for histopathological examination, were kept for fixation in $10 \%$ neutral buffered formalin for $24 \mathrm{hrs}$. They were cut into two halves, through hilum and were embedded in paraffin blocks. 3-micron sections were made with microtome and stained with hematoxylin and eosin.

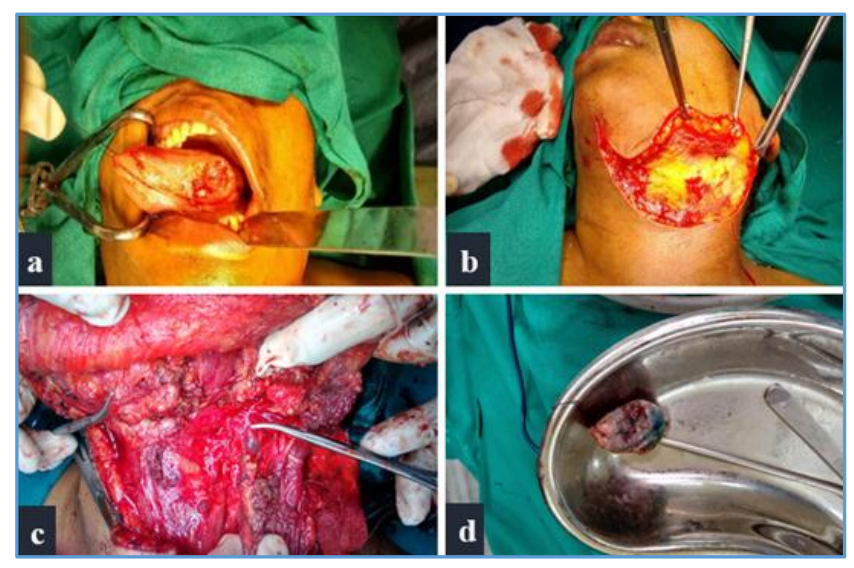

Figure 1. a-Showing Oral Cancerous Lesion, b- Neck Incision,

c-Sentinel Node Identification by Dye, d-Sentinel Node Removal

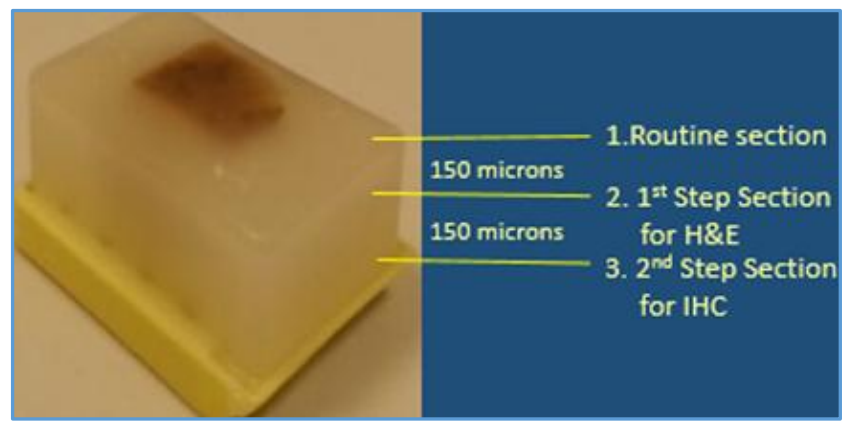

Figure 2. Method of Step Sectioning on Tissue Block

Initially, only few ( 6 cases) of the cases were positive for metastatic deposits on routine histopathological evaluation. The negative tissues (sentinel nodes) were subjected to step serial sectioning (method of step serial section illustrated in Figure 2) and immunohistochemistry was performed. With an interval of 150 microns from initial routine section, 1 section was taken for H\&E and again after interval of 150 microns, 1 section was taken for Immuno-Histochemistry (IHC) with Pancytokeratin as the marker. Totally 3 sections were obtained at 3 different steps (levels). And the results were analysed.11-15

\section{RESULTS}

Total no of cases included in the study were 20 , with an age range of 25 to 65 years and male to female ratio being 2:1. The most common sites of oral cancerous lesions in the present study were tongue followed by buccal mucosa and gingivo buccal sulcus. The primary lesion size varied between $2 \times 2 \mathrm{cms}$ to $5 \times 6 \mathrm{cms}$. Number of sentinel nodes in each case varied from 1 to 5 . (Results are explained in tables 1, 2, 3, 4, chart 1 , and figure 3 )

\begin{tabular}{|c|c|}
\hline Total No. of Cases & $\mathbf{2 0}$ \\
\hline Sentinel Node Identified In & 16 \\
\hline Sentinel Node Not Identified In & 04 \\
\hline Table 1 \\
\hline \multicolumn{2}{|c|}{$\mid$} \\
\hline Sentinel Node Identified In & $\mathbf{1 6}$ \\
\hline Positive for Metastasis & 06 \\
\hline Negative for Metastasis & 10 \\
\hline Table 2 \\
\hline
\end{tabular}

\begin{tabular}{|c|c|}
\hline Lymph Nodes Subjected to Step Sectioning & $\mathbf{1 0}$ \\
\hline Nodes turned out to be Positive after Step Sectioning & 01 \\
\hline Nodes remained Negative after Step Sectioning & 09 \\
\hline Table 3 \\
\hline
\end{tabular}

\begin{tabular}{|c|c|c|c|}
\hline Type of Histological Evaluation & Positive & Negative & Total \\
\hline $\begin{array}{l}\text { On Routine Evaluation } \\
\text { (Before Step Sectioning) }\end{array}$ & 06 & 10 & 16 \\
\hline After Step Sectioning & 07 & 09 & 16 \\
\hline \multicolumn{4}{|c|}{$\begin{array}{l}\text { Table 4. Therefore, Total no. of Cases in which Sentinel } \\
\text { Nodes Identified-16 }\end{array}$} \\
\hline
\end{tabular}

$\mathrm{P}$ value calculated for the above data which is 0.718894 , and this result is not significant as $\mathrm{p}<0.05$. 

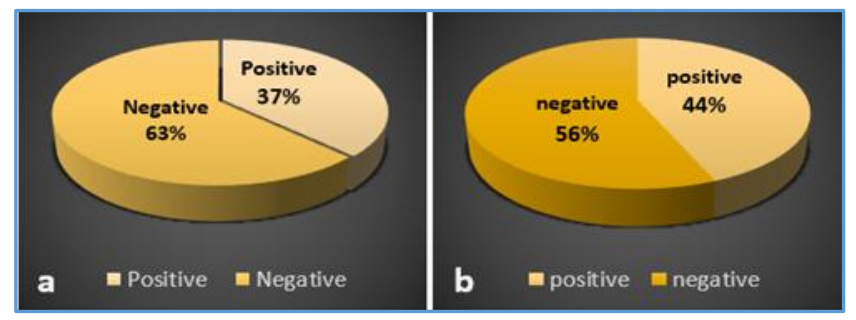

Chart 1. a. On Routine Evaluation (Before Step Sectioning) b. After Step Sectioning

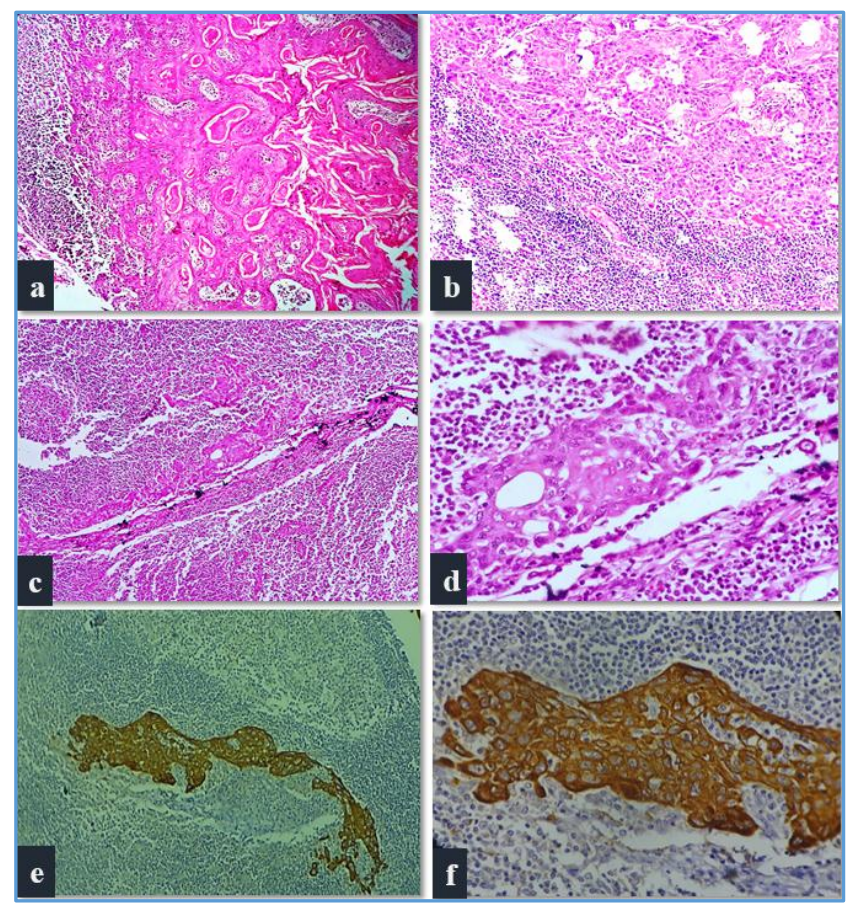

Figure 3. $a$ \& b-Sections of Nodes Positive on Initial Routine Sectioning

$c \& d$-Sections of Node that are Positive after Step Sectioning at $1^{\text {st }}$ Step Section Level (c- Low Power View and d-High Power View)

$e \& f$-Sections of the Same Node at $2^{\text {nd }}$ Step Section Level showing Positivity with Pan Cytokeratin as IHC Marker (e-Low Power View and f-High Power View)

\section{DISCUSSION}

More than $50 \%$ of the patients with oral squamous cell carcinoma have lymph node metastasis. Staging of the neck by palpation and imaging techniques are based primarily on size criteria and the nodes smaller than $10 \mathrm{~mm}$ are not generally considered suspicious. ${ }^{16}$ However, lymph nodes as small as $2.0 \mathrm{~mm}$ can also contain metastatic disease. 17

According to UICC (The Union for International Cancer Control) ${ }^{18}$ definitions - metastatic deposits to lymph nodes can be-

\section{Micro Metastasis}

Tumour deposit between $0.2 \mathrm{~mm}$ and $2.0 \mathrm{~mm}$ in largest dimension.

\section{Isolated Tumour Cells}

- Tumour cells $\leq 0.2 \mathrm{~mm}$.

- $\quad$ Single cells, small clusters.

- No stromal reaction.

- No contact with vessel wall.
There is still a $20-30 \%$ incidence of Occult nodal metastasis in necks, which are wrongly categorized as $\mathrm{N}_{0}$. The prognosis of the Patients with occult metastatic disease (which should be categorized as N1) of any size is worse than $\mathrm{N}_{0}$ patients, and further becomes worse with increasing nodal involvement. Failure of providing aggressive treatment approach in case of $\mathrm{N} 1$ disease may lead to regional recurrences and leads to bad prognosis. Hence exact status of lymph node involvement is crucial in staging of the $\mathrm{N}_{0}$ neck and management.

Metastases in other lymph nodes is expected to be common when a micro metastasis is detected in a sentinel lymph node. Sentinel node biopsy is now routinely used in case of breast cancer \& malignant melanoma. Sentinel node biopsy in case of $\mathrm{T} 1 / \mathrm{T} 2$ stage $\mathrm{N}_{0}$ Oral squamous cell carcinoma has gained the popularity in recent years, as an alternative to elective neck dissection for identifying occult cervical metastasis.

Sentinel node biopsy has been included in NCCN guidelines for management of oral cancer ${ }^{19}$ since 2014. The advantages of sentinel node biopsy are:

1. Minimally invasive procedure.

2. Prevents unnecessary removal of functional lymph nodes.

3. Identifies skip metastasis, and unpredictable lymphatic drainage.

4. Decreased morbidity.

5. Pathological handling of the specimen is easy when compared with neck nodes

And the main disadvantage, is to do the surgery again (Neck dissection), if nodes turn out to be positive for metastasis.

Sentinel node biopsy for oral squamous cell carcinoma, is practised only in centres where expertise for this procedure is available. L.P. Kowalski, et $\mathrm{al}^{20}$ in 2007 stated that the number of elective neck dissections which were negative for metastasis could be as high as $80 \%$ indicating (Negative neck dissection rate) unnecessary removal of normal functioning lymphatics at the cost of high morbidity. In the Present study, as per the NCCN 20 (National Comprehensive Cancer Network) treatment guidelines, neck dissection was needed only for cases, in which sentinel nodes were not identified (4 cases) and for those positive for metastasis (7 cases). So, surgery was needed in total of 11 cases only, but, was done in 20 cases. Actually, surgery was not needed in 9 cases. Therefore, the negative neck dissection rate in our study was $45 \%$.

Pitman $\mathrm{K} \mathrm{T}$ et $\mathrm{al}^{21}$ studied the feasibility and accuracy of sentinel node biopsy in HNSCC and established that sentinel node biopsy is a technically feasible, minimally invasive method for staging the regional lymphatics in patients with $\mathrm{N}_{0}$ HNSCC.

Murer et $\mathrm{al}^{22}$ in 2011 established that sentinel node biopsy is associated with significantly less post-operative morbidity and better shoulder function than elective neck dissection.

In study of Riguel and colleagues ${ }^{23,} 24$ done in 2013 stated that Sentinel Node biopsy is a useful procedure for pathological staging of the $\mathrm{cN}_{0}$ neck in previously untreated patients with oral cancer.

Seraina denoth et $\mathrm{al}^{25}$ studied to assess the threedimensional distribution of metastatic tumour cells within sentinel node in oral squamous cell carcinoma. They concluded that with step serial sectioning the detection rate of micro metastasis and isolated tumour cells was increasing 
in subsequent sections, it was found that micro metastasis and isolated tumour cells were not randomly distributed, rather showed predominance in central planes close to the lymphatic inlet. Hence site of distribution is also important.

In the present study, though the result was statistically not significant the negative neck dissection rate was decreased after step serial sectioning. Hence more studies by using large sample size are recommended, to establish the role of sentinel lymph node biopsy in management of oral squamous cell carcinoma.

\section{CONCLUSION}

In centers practicing sentinel lymph node biopsy for staging of Oral Squamous Cell Carcinoma, meticulous histopathological workup on entire lymph node by taking more number of sections at different levels using step serial sections is needed, so as to detect micro metastasis and isolated tumour cells. Because the primary goal of sentinel node biopsy is a more accurate staging of the clinically nodal negative neck (of T1-T2 oral squamous cell carcinoma) thereby avoiding unnecessary radical neck dissection and postoperative morbidity associated with it.

\section{ACKNOWLEDGEMENT}

The authors would like to thank the Department of Surgical Oncology for their help and support during the study, and also would like to thank the technical staff of Department of Pathology, MNJ Institute of Oncology and Regional Cancer Centre, Hyderabad, Telangana, India.

\section{REFERENCES}

[1] Calabrese L, Bruschini R, Ansarin M, et al. Role of sentinel lymph node biopsy in oral cancer. Acta Otorhinolaryngol Ital 2006;26(6):345-9.

[2] Byakodi R, Byakodi S, Hiremath S, et al. Oral cancer in India: an epidemiologic and clinical review. J Community Health 2012;37(2):316-9.

[3] Pitman KT, Johnson JT, Myers EN. Effectiveness of selective neck dissection for management of the clinically negative neck. Arch Otolaryngology Head Neck Surg 1997;123(9):917-22.

[4] Steiner W, Hommerich CP. Diagnosis and treatment of the N0 neck of carcinomas of the upper aerodigestive tract. Eur Arch Otorhinolaryngol 1993;250(8):450-6.

[5] Antonio JK, Santini S, Politi D, et al. Sentinel lymph node biopsy in squamous cell carcinoma of the head and neck: 10 years of experience. Acta Otorhinolaryngol Ital 2012;32(1):18-25.

[6] Serrano-Vicente J. The role of sentinel node biopsy in oral squamous cell carcinoma. Plast Aesthet Res 2016;3:142-9.

[7] Alkureishi LW, Burak Z, Alvarez JA, et al. Joint practice guidelines for radionuclide lymphoscintigraphy for sentinel node localization in oral/oropharyngeal squamous cell carcinoma. Ann Surg Oncol 2009;16(11):3190-210.

[8] Jacob TE, Malathi N. Sentinel lymph node biopsy in patients with oral cancer. Health Sciences 2013;4(2):JS004C.

[9] Lawrence L. Sentinel node biopsy adequate for staging oral cancer: Cancer Network (Http://Www.Cancernetwork.Com/ Head \& Neck Cancer) Jul 29, 2013.
[10] Thevarajah S, Huston TL, Simmons RM. A comparison of the adverse reactions associated with isosulfan blue versus methylene blue dye in sentinel lymph node biopsy in breast cancer. Am J Surgery 2005;189(2):236-9.

[11] Stoeckli SJ, Pfaltz M, Steinert H, et al. Histopathological features of occult metastasis detected by sentinel lymph node biopsy in oral and oropharyngeal squamous cell carcinoma. Laryngoscope 2002;112(1):111-5.

[12] Hermanek P, Hutter RV, Sobin LH, et al. International Union Against Cancer. Classification of isolated tumour cells and micrometastasis. Cancer 1999;86(12):2668-73.

[13] Riber-Hansen R, Nyengaard JR, Hamilton-Dutoit SJ, et al. The nodal location of metastases in melanoma sentinel lymph nodes. Am J Surg Pathol 2009;33(10):1522-8.

[14] Weaver DL, Ashikaga T, Krag DN, et al. Effect of occult metastases on survival in node-negative breast cancer. N Engl J Med 2011;364(5):412-21.

[15] Stoeckli SJ, Pfaltz M, Ross GL, et al. The second international conference on sentinel node biopsy in mucosal head and neck cancer. Ann Surg Oncol 2005;12(11):919-24.

[16] Hornstra MT, Alkureishi LW, Ross GL, et al. Predictive factors for failure to identify sentinel nodes in head and neck squamous cell carcinoma. Head Neck 2008;30(7):858-62.

[17] Don DM, Anzai Y, Lufkin RB, et al. Evaluation of cervical lymph node metastases in squamous cell carcinoma of the head and neck. Laryngoscope 1995;105(7 Pt 1):669-74.

[18] International Union Against Cancer (UICC), prognostic factors in cancer. $3^{\text {rd }}$ edn. New York: Wiley-Liss Publisher 2006.

[19] NCCN Guidelines Version 1. Cancer of the oral cavity. 2015.

[20] Kowalski LP, Sanabria A. Elective neck dissection in oral carcinoma: a critical review of the evidence. Acta Otorhinolaryngol Ital 2007;27(3):113-7.

[21] Pitman KT, Johnson JT, Brown ML, et al. Sentinel lymph node biopsy in head and neck squamous cell carcinoma. Laryngoscope 2002;112(12):2101-13.

[22] Murer K, Huber GF, Haile SR, et al. Comparison of morbidity between sentinel node biopsy and elective neck dissection for treatment of the n0 neck in patients with oral squamous cell carcinoma. J Head Neck 2011;33(9):1260-4.

[23] Rigual N, Douglas W, Lamonica D, et al. Sentinel lymph node biopsy: a rational approach for staging T2N0 oral cancer. Laryngoscope 2005;115(12):2217-20.

[24] Rigual N, Loree T, Frustino J, et al. Sentinel node biopsy in lieu of neck dissection for staging oral cancer. JAMA Otolaryngol Head Neck Surg 2013;139(8):779-82.

[25] Denoth S, Broglie MA, Haerle SK, et al. Histopathological mapping of metastatic tumour cells in sentinel lymph nodes of oral and oropharyngeal squamous cell carcinomas. Head Neck 2015;37(10):1477-82. 